\title{
SEMIÓTICA E ASPECTUALIDADE EM POEMAS DE MANUEL BANDEIRA*
}

\section{SEMIOTICS AND ASPECTUALIZATION IN POEMS BY MANUEL BANDEIRA}

\author{
Dayane Celestino de Almeida \\ USP - Universidade de São Paulo
}

Resumo: $\mathrm{O}$ aspecto vem sendo estudado há muito pela lingüística e foi incorporado mais recentemente pelos estudos semióticos. Este trabalho tem por objetivo apresentar partes de análises de alguns poemas de Manuel Bandeira, com foco na aspectualidade desses textos.

Palavras-chave: semiótica; poesia; aspectualidade; Manuel Bandeira.

Abstract: The aspect has been studied by the linguistics for a long time and it has been incorporated more recently by the semiotics. This paper intends to present parts of some analysis of poems by Manuel Bandeira, focusing on the aspectualization in these texts.

Keywords: semiotics; poetry; aspectualization; Manuel Bandeira.

\section{Aspecto e aspectualidade}

O aspecto vem sendo estudado pela lingüística há bastante tempo e foi, mais recentemente, incorporado pelos estudos semióticos do discurso. A lingüística o define como a maneira de ser da ação ou como um ponto de vista sobre um processo, no que diz respeito a sua duração. Camara Jr. (1977, p. 141) nos explica esse conceito com o seguinte exemplo:

Distingue-se, por exemplo, uma ação que principia, como em partir, uma que termina como em chegar, uma que se desdobra, sem alusão ao início ou ao fim como andar, viajar, uma que se repete, com em saltitar, etc.

A semiótica estende a noção de aspecto para além da temporalidade: à espacialidade, à actorialidade e à axiologia, conforme Bertrand (2003, p.416). Esta noção também é estendida, na medida em que os estudos sobre o aspecto realizados pela lingüística são geralmente relacionados ao verbo, e a semiótica postula que o aspecto pode incidir sobre enunciados inteiros (frases, parágrafos, etc.) e também sobre outras classes gramaticais.

\footnotetext{
* Trabalho realizado com o apoio do PIBIC/CNPq.
} 
No Dicionário de Semiótica (GREIMAS; COURTÉS, 1983, p. 28) o verbete "aspectualização" traz a seguinte definição:

No quadro do percurso gerativo, compreender-se-á por aspectualização a disposição, no momento da discursivização, de um dispositivo de categorias aspectuais mediante as quais se revela a presença implícita de um actante observador. Esse procedimento parece ser geral e caracterizar os três componentes, que são a actorialização, a espacialização e a temporalização, constitutivos dos mecanismos de debreagem.

Sendo o aspecto definido pela lingüística como o "ponto de vista sobre a ação", a semiótica precisou introduzir um actante observador, que é o que terá esse "ponto de vista", ou melhor, é aquele que avaliará o processo: "as categorias aspectuais só se explicam pela presença do observador, que se pronuncia implicitamente sobre o fazer do sujeito no momento de sua conversão em processo" (GREIMAS; COURTÉS, 1983, p. 314).

A semiótica considera que os processos são caracterizados pelos semas ${ }^{1}$ duratividade ou pontualidade, perfectividade ou imperfectividade, incoatividade ou terminatividade.

Sintagmaticamente ${ }^{2}$, os semas incoatividade, duratividade e terminatividade formam uma categoria aspectual. É o que mostra o esquema a seguir (BARROS, 2001, p.91):

$\begin{aligned} & \text { incoativo } \\ & \text { (pontual) }\end{aligned}$
$\begin{gathered}\text { durativo } \\ \text { (descontínuo } \\ \text { ou contínuo) }\end{gathered}$$\rightarrow \quad \rightarrow \quad \begin{gathered}\text { terminativo } \\ \text { (pontual) }\end{gathered}$

Esquema I: Incoatividade $v s$ Terminatividade

Por outro lado, paradigmaticamente, o sema duratividade faz parte da categoria duratividade/pontualidade. Ainda considerando o eixo paradigmático, encontramos a categoria perfectividade/imperfectividade. Do ponto de vista sintagmático, a pontualidade pode marcar o início ou o fim de um processo. Vejamos a figura abaixo (BARROS, 2001, p.91):

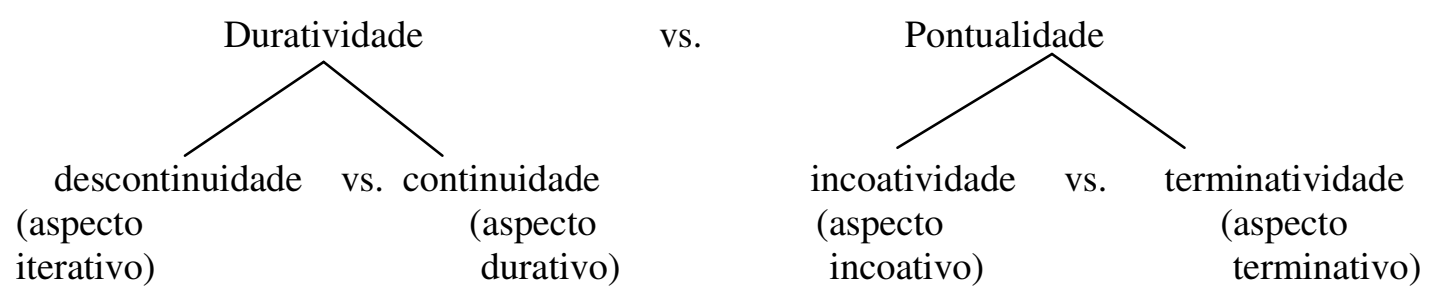

Esquema II: Duratividade vs Pontualidade

Já os semas perfectividade e imperfectividade correspondem, respectivamente, aos aspectos terminativo ou durativo. Assim, considerando que pontualidade, perfectividade e

\footnotetext{
1 “o sema é a unidade mínima da significação (...) sinônimo de traço semântico (...)”.(DUBOIS et al., 2004, p. 526)

${ }^{2}$ Para as noções de "sintagma" e "paradigma", Cf. (SAUSSURE, 2002, p. 142). 
imperfectividade sempre esbarram de algum modo em incoatividade, duratividade ou terminatividade, podemos considerar apenas estes três últimos semas quando nos referimos à aspectualização. Isto vai ao encontro do que diz Zilberberg (apud Tatit, 2001, p.49), ao afirmar que a aspectualidade: "conteria apenas valores demarcatórios, ou de 'limite' ('saliências') e valores segmentais ou de 'gradação' ('passâncias')". Os aspectos incoativo e terminativo derivam dos primeiros, ao passo que os outros geram a duratividade.

$\mathrm{O}$ esquema a seguir ${ }^{3}$ esquematiza bem o que acabamos de apresentar:

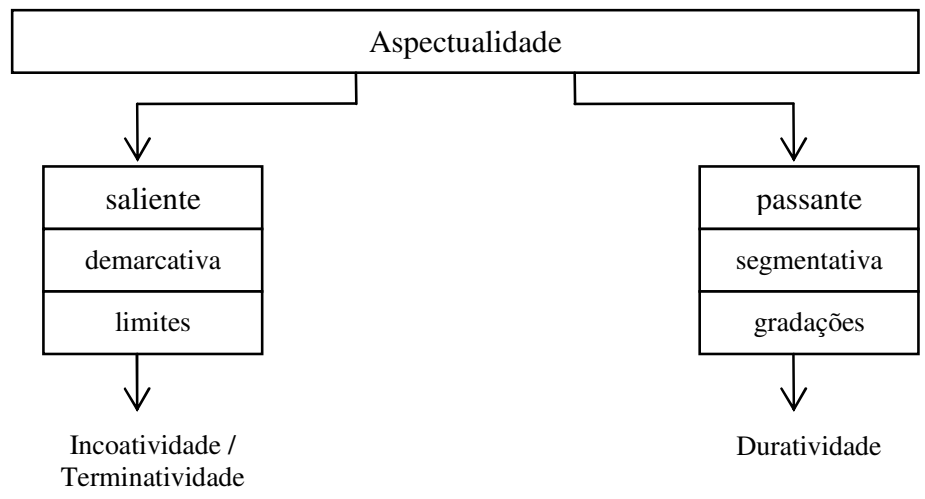

Esquema III: Aspectualidade

Na próxima seção, apresentamos uma análise da aspectualidade em alguns poemas de Manual Bandeira. As transcrições desses textos encontram-se ao fím deste trabalho, no item Anexos.

\section{A aspectualidade nos poemas analisados}

O primeiro poema de Manuel Bandeira que analisamos é "Desencanto", publicado em A cinza das horas (livro de estréia de Bandeira) em 1917. O estudo sobre aspectualidade que ora apresentamos fez parte de outro estudo já publicado (ALMEIDA, 2007a).

Já numa primeira leitura, percebemos que este é um poema que fala sobre a poesia e descreve o verso: o fazer poético como um instrumento de desabafo, uma válvula de escape de um sujeito que sofre e que espera a morte. Diante de tal definição, podemos pensar o estado juntivo do sujeito e dizer que ele está em não-conjunção com o objeto-valor, uma vez que perdeu as ilusões. Assim, consideramos que o estado passional do sujeito é o da insatisfação, uma vez que, em termos modais, ele quer-ser, não-crê-ser e sabe-não-poderser/estar em conjunção com o objeto e, em termos juntivos, seu estado é o da não-conjunção com o objeto 'esperança' ou 'ilusões'. Em contrapartida, está em conjunção com o sofrimento causado pela espera da morte, uma conjunção não desejada. A falta vivida pelo sujeito pode se resolver de duas maneiras, conforme Barros (2003, p. 51): "pela reparação ou pela resignação e conformação". No texto em questão, é a segunda opção que vigora, uma vez que o sujeito faz versos de desalento (que significa, segundo o dicionário Houaiss, "estado de quem se mostra sem ânimo, desânimo, abatimento") e, na terceira estrofe, vemos um sujeito

\footnotetext{
${ }^{3}$ Adaptado de LOPES, I.C. Aspectualidade, limiares e limites. Comunicação no 54 Encontro do GEL (2006).
} 
conformado diante da idéia de que não mais conseguirá sair daquela situação, como indicado pelo verso Assim dos lábios a vida corre, em que a conjunção Assim indica essa noção de conformidade, intensificada pelo verso final - Eu faço versos como quem morre, mostrando que o sujeito está tão resignado que apenas espera a morte. Resumindo, percebemos a existência de um sujeito insatisfeito, triste e resignado. É esse estado de desencanto, mágoa e resignação do sujeito do enunciado que serve de matéria para o sujeito da enunciação compor o poema.

Como esse sujeito não quer fazer nada, está resignado e apenas espera a morte, vemos que há uma aspectualização do seu comportamento. Esse sujeito "vive" esperando o fim (destaque para o ultimo verso: Eu faço versos como quem morre; espécie de resumo do que ele falou antes e também a conclusão do poema). Portanto, podemos dizer que esse comportamento tem um aspecto terminativo. A terminatividade é encontrada muitas vezes ao longo do poema. Por exemplo, no próprio último verso, que já citamos, encontra-se a palavra morre, portadora de um aspecto terminativo. Outros elementos do poema que remetem a um aspecto terminativo são:

(1) desencanto (é o estado de quem perdeu as ilusões, ou seja, sem ilusões);

(2) A expressão fecha meu livro.

(3) Meu verso é sangue (figura do sangue associada à morte).

(4) Os adjetivos ardente e quente que correspondem a uma sensação de queimar, de algo queimando. De acordo com o dicionário Houaiss, queimar é "destruir pelo fogo, fazer em cinzas", novamente o aspecto terminativo.

(5) A expressão a vida corre. Aqui, o verbo correr considerado sozinho portaria um aspecto durativo, mas junto de vida, na expressão a vida corre, que significa a vida se esvai, a vida acaba, o aspecto é terminativo.

(6) A expressão cai gota a gota tem o verbo cair, com aspecto terminativo. Já gota a gota poderia ser associada à duratividade. Porém, no contexto do poema essa expressão ajuda a reforçar a idéia de que a morte vai chegar paulatinamente, devagar. Desta forma, podemos considerar a expressão cai gota a gota como portadora de um aspecto terminativo e dizer que essa terminatividade ocorre num andamento lento. Quanto a esse andamento lento, o mesmo acontece em $a$ vida corre, no poema, seguida por deixando (a vida corre deixando um acre sabor...). O gerúndio deixando também indica um andamento lento da terminatividade dada por a vida corre (corre, nesse contexto, perde seu traço de "rapidez").

Voltando um pouco ao ponto em que falamos sobre o sujeito estar insatisfeito, magoado e resignado, observemos uma passagem de Barros (2001, p.65):

A insatisfação e a decepção podem ser determinadas aspectualmente pela duração e prolongar-se em novos efeitos passionais: a mágoa que perdura ou a resignação, por exemplo.

Essa afirmação nos leva a ver que a mágoa e resignação do sujeito em "Desencanto" são determinadas aspectualmente, e vai ao encontro do que acabamos de falar sobre o andamento lento. Foi essa demora, essa duração ou andamento lento que intensificaram o sofrimento do sujeito, porque ele está "desencantado", perdeu as ilusões, a esperança, sabe que vai morrer, mas a morte não vem rápido. Ele vive na iminência da morte 
e a demora é que gera a tristeza e a resignação. Quanto mais lento é o andamento, maior é o sofrimento. Fazendo uma ponte com o nível discursivo, podemos verificar esta tristeza do sujeito figurativizada em pranto, tristeza esparsa, remorso vão, sangue, dói-me, amargo, acre. Tudo isso culmina na angústia rouca descrita no poema. Coelho (1982, p. 13) também comenta essa lentidão: "A certa altura, o processo de morrer, que se arrasta em agonia lenta e gotejante, confunde-se ao próprio ato de escrever: a tinta vira sangue, a tinta é sangue".

Em conclusão, o que procuramos mostrar aqui foi como o comportamento terminativo do sujeito foi sendo corroborado e reiterado pelo aspecto presente em vários elementos pontuais ao longo do poema, e também como essa rede aspectual foi fundamental para a construção de sentido no texto.

O segundo poema estudado é "Poética", que integra o quarto livro de poemas de Manuel Bandeira, Libertinagem, publicado em 1930. Este é um poema que "se celebrizou como um manifesto modernista em versos" (MOURA, 2001, p. 52). Podemos perceber que nele o autor expressa como deveria ou não deveria ser a poesia, de acordo com a sua perspectiva, paralela aos preceitos modernistas.

Sobre a aspectualidade nesse texto, considerando o que afirma Zilberberg (apud TATIT, 2001, p. 49), ao sustentar que a aspectualidade "conteria apenas valores demarcatórios, ou de 'limite' ('saliências') e valores segmentais ou de 'gradação' ('passâncias')", verificamos que estão presentes os valores de limite, como se pode ver principalmente pela expressão Estou farto, presente muitas vezes ao longo do poema e que remete a um aspecto terminativo. Por outro lado, se considerarmos que, ao propor a ruptura com as poéticas vigentes, o sujeito também anuncia que quer outros valores em troca, podemos afirmar que o aspecto é incoativo, pois uma ação vai começar. O aspecto é o ponto de vista sobre um processo e "Poética" apresenta dois deles: um que está ao fim e um que está por começar. A mesma coisa acontece se observarmos separadamente o verso Estou farto do lirismo que pára e vai averiguar no dicionário o cunho vernáculo de um vocábulo, onde estão presentes duas ações: uma que pára (aspecto terminativo) e uma que se inicia - vai averiguar - (aspecto incoativo).

Podemos também associar a aspectualidade à idéia de continuidade versus descontinuidade. Zilberberg (2006b, p. 251) afirma que, por um lado, a continuação - a parada da parada - dá lugar à "passância" e gera graus e limiares e, por outro, a parada - no sentido de continuação da parada - dá lugar à "saliência" e gera limites. Em "Poética", no que diz respeito à continuidade versus descontinuidade, o sujeito, ao propor uma ruptura com os valores preestabelecidos e acolher, logo em seguida, novos valores, está afirmando a descontinuidade. Em primeiro lugar, ele propõe uma "parada da continuação", mas ao afirmar os novos valores que agora quer, ele finaliza o percurso afirmando uma "continuação da parada" e inserindo-se, em termos tensivos, numa área de retenção, conforme o quadrado semiótico abaixo: 


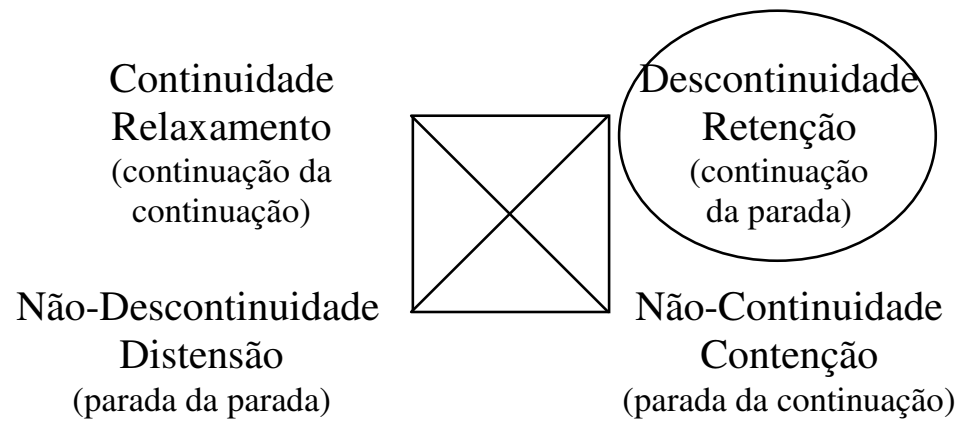

Esquema IV: Continuidade e descontinuidade

O que acabamos de explicar é, portanto, mais uma evidência de que "Poética" é construído levando em conta uma aspectualização da ordem dos limites.

O próximo poema estudado é "Nova Poética", integrante do livro Belo Belo (1948). O poema, que lança "a teoria do poeta sórdido", vem ratificar a proposta poética que Bandeira vinha delineando havia trinta anos, ou seja, desde a publicação de "Os Sapos", em 1919 (Carnaval).

$\mathrm{Na}$ primeira estrofe, a partir do verso 4 , a debreagem de pessoa muda de enunciativa para enunciva e uma pequena cena é contada pelo narrador:

Vai um sujeito. / Sai um sujeito de casa com a roupa de brim branco muito bem engomada, e na primeira esquina passa um caminhão, salpica-lhe o paletó ou a calça de uma nódoa de lama: / É a vida.

No nível narrativo, encontramos um sujeito que está a caminhar (já dotado de competências para tal, pois está com a roupa própria para isso) e de repente tem o seu fazer interrompido pela ação de um anti-sujeito (o caminhão), que "fere" a sua competência, sujando-lhe a roupa. Ao espirrar lama no andante, o caminhão causa uma ruptura, uma quebra na continuidade. O sujeito fica impedido de continuar o seu programa. Zilberberg (2006b, p. 133) adotou para tal ocorrência o nome de "parada" e diz que à parada corresponde um "fazer remissivo", em oposição a um "fazer emissivo" ou "continuativo". Ocorrem, pois, duas passagens: da continuação para a parada e do relaxamento para a tensão. Vemos, ainda, uma relação contrária entre os planos da expressão e do conteúdo, no que diz respeito à aceleração: há uma desaceleração, devido à parada, no plano do conteúdo, mas, no plano da expressão, há uma aceleração e uma afirmação da continuidade do fluxo narrativo, sendo este um trecho em prosa dentro do poema. O estado inicial (sujeito "relaxado") é recuperado quando o narrador declara É a vida (verso 6), numa conclusão/explicação que indica conformidade com a situação.

Quanto ao aspecto, podemos contrapor as duas ações. A primeira é o andar do sujeito pela rua e é uma ação que dura, progride no tempo e no espaço. Corresponde, portanto, a uma aspectualidade durativa. Já a ação do caminhão, que provoca a parada, é uma ação que finaliza um processo, impõe uma descontinuidade, sendo a aspectualidade aqui relacionada ao limite. Os valores de limite geram a supressão da continuidade (ZILBERBERG, 1993).

A parada, nesse caso, é o resultado da interrupção brusca do fazer. O momento em que o caminhão passa e joga lama no sujeito tem a duração menor do que o fazer do sujeito (que passeia) e é um momento muito rápido. Isso corresponde ao que afirma

\footnotetext{
${ }^{4}$ Cf. ALMEIDA, 2007 b.
} 
Zilberberg (2006a, p.171) acerca do andamento: "O andamento rege a duração por uma correlação inversa (...). Quanto mais elevada é a velocidade, menos longa é a duração" 5 . Esse momento rápido é um fator que favorece a aspectualidade saliente, demarcativa, de limites. Conforme Zilberberg (1993, p. 6) "la valeur de la vitesse règle la manifestation des deux fonctions aspectuelles indiquées: la vitesse élevée et l'accélération favorisent la démarcation (...)”.

Por fim, faremos um breve comentário sobre a aspectualidade em "O último poema", publicado em 1930 no livro Libertinagem, sendo o texto o último poema do livro. A questão central que se coloca no texto é a defesa de uma poesia ligada a temas ou imagens simples ou cotidianas e também uma valorização da essência das coisas. Predomina em "O último poema" o aspecto terminativo. Dos cinco verbos existentes, dois apresentam claramente o aspecto terminativo: matam e consomem. Remetem ao mesmo aspecto os adjetivos último, ardente (algo que "queima", que se consome em chamas, segundo o dicionário Houaiss) e suicidas, pois o suicídio leva à morte, ou seja, ao fim de todos os processos.

Podemos falar ainda em um comportamento terminativo, visto que o sujeito deste poema "vive" em função do último poema: desde o título já se percebe essa terminatividade, reforçada pelos elementos do poema. Notemos, ainda, que o aspecto terminativo é mais forte justamente no primeiro verso (com o adjetivo último) e no último, que fala sobre os suicidas.

Com este trabalho, procuramos mostrar como as noções de aspecto e aspectualidade podem ser utilizadas de maneira bastante proveitosa nas análises de textos.

\section{Referências bibliográficas:}

ALMEIDA, D. C. de. Análise semiótica de "Desencanto", de Manuel Bandeira. Estudos Semióticos, São Paulo, no . 3, 2007a. Disponível em <www.fflch.usp.br/dl/semiotica/es>. Acesso em 2007.

BANDEIRA, M.. Estrela da vida inteira. Rio de Janeiro: Nova Fronteira, 1993.

BARROS, D. L. P. de. Teoria do discurso: fundamentos semióticos. São Paulo: Humanitas, 2001.

Teoria semiótica do texto. São Paulo: Ática, 2003.

BERTRAND, D.. Caminhos da semiótica literária. Tradução do Grupo CASA. Bauru, SP: EDUSC, 2003.

CAMARA JR., J. M.. Uma categoria verbal: o aspecto. In: Princípios de lingüística geral. Rio de Janeiro: Padrão, 1977.

COELHO. J. F. Manuel Bandeira pré-modernista. Rio de Janeiro: José Olympio; Brasília: INL, 1982.

\footnotetext{
${ }^{5}$ Interessante observar que justamente esse momento rápido, pontual, uma seqüência de consoantes oclusivas, destacando-se uma alternância entre [p] e [k]: na primeira esquina passa um caminhão, salpica-lhe o paletó ou a calça (...).
} 
CASA, Vol.6 n.2, dezembro de 2008

GREIMAS, Algirdas. J. \& COURTÉS, Joseph. Dicionário de Semiótica. Tradução de Alceu Dias Lima e outros. São Paulo: Cultrix, 1983.

LOPES, I. C. Aspectualidade, limiares e limites. In: 54º SEMINÁRIO DO GEL, 2006, Franca. Comunicação.

MOURA, M. M. Manuel Bandeira. São Paulo: Publifolha, 2001.

SAUSSURE, F. de. Curso de Lingüística Geral. Tradução de Antônio Cheline, José Paulo Paes e Izidoro Blikstein. São Paulo: Cultrix, 2002.

TATIT, Luiz. Análise semiótica através das letras. São Paulo: Ateliê Editorial, 2001.

ZILBERBERG, Claude. Síntese da gramática tensiva. In: Revista Significação, Número 25, São Paulo, Annablume, 2006a.

Razão e poética do sentido. Tradução de Ivã Lopes; Luiz Tatit; Waldir Beividas. São Paulo: Edusp, 2006b.

Seuils, limites, valeurs. 1993. Disponível em <http://www.claudezilberberg.net/>. Acesso em 15 dez 2007.

\section{Anexos}

\section{DESENCANTO}

Eu faço versos como quem chora

De desalento... de desencanto...

Fecha o meu livro, se por agora

Não tens motivo nenhum de pranto.

Meu verso é sangue. Volúpia ardente...

Tristeza esparsa... remorso vão...

Dói-me nas veias. Amargo e quente,

Cai, gota a gota, do coração.

E nestes versos de angústia rouca

Assim dos lábios a vida corre,

Deixando um acre sabor na boca.

— Eu faço versos como quem morre.

Teresópolis, 1912

\section{POÉTICA}

Estou farto do lirismo comedido

Do lirismo bem comportado 
CASA, Vol.6 n.2, dezembro de 2008

Do lirismo funcionário público com livro de ponto expediente protocolo e [manifestações de apreço ao sr. diretor

Estou farto do lirismo que pára e vai averiguar no dicionário o cunho verná[culo de um vocábulo

\section{Abaixo os puristas}

Todas as palavras sobretudo os barbarismos universais Todas as construções sobretudo as sintaxes de exceção Todos os ritmos sobretudo os inumeráveis

Estou farto do lirismo namorador

Político

Raquítico

Sifilítico

De todo lirismo que capitula ao que quer que seja fora de si mesmo.

De resto não é lirismo

Será contabilidade tabela de co-senos secretário do amante exemplar com [cem modelos de cartas e as diferentes [maneiras de agradar às mulheres, etc.

Quero antes o lirismo dos loucos

O lirismo dos bêbedos

O lirismo difícil e pungente dos bêbedos

O lirismo dos clowns de Shakespeare

- Não quero mais saber do lirismo que não é libertação.

\section{NOVA POÉTICA}

Vou lançar a teoria do poeta sórdido.

Poeta sórdido:

Aquele em cuja poesia há a marca suja da vida.

Vai um sujeito.

Sai um sujeito de casa com a roupa de brim branco muito bem engomada, e [na primeira esquina passa um caminhão, salpica-lhe

É a vida.

[o paletó ou a calça de uma nódoa de lama:

O poema deve ser como a nódoa no brim:

Fazer o leitor satisfeito de si dar o desespero.

Sei que a poesia é também orvalho.

Mas este fica para as menininhas, as estrelas alfas, as virgens cem por cento e [as amadas que envelheceram sem maldade. 
CASA, Vol.6 n.2, dezembro de 2008

19 de maio de 1949

\section{O ÚLTIMO POEMA}

Assim eu quereria o meu último poema

Que fosse terno dizendo as coisas mais simples e menos intencionais

Que fosse ardente como um soluço sem lágrimas

Que tivesse a beleza das flores quase sem perfume

A pureza da chama em que se consomem os diamantes mais límpidos

A paixão dos suicidas que se matam sem explicação. 